\title{
2S state and Lamb shift in muonic hydrogen
}

\section{Randolf Pohl}

Published online: 2 October 2009

(C) The Author(s) 2009. This article is published with open access at Springerlink.com

\begin{abstract}
The metastable $2 \mathrm{~S}$ state in muonic hydrogen is particularily interesting because a measurement of the Lamb shift could reduce the uncertainty in the proton charge radius by an order of magnitude. The most important prerequisite for such a measurement is a sufficiently large population and lifetime of the $2 \mathrm{~S}$ state. We have determined the long-lived and short-lived $2 \mathrm{~S}$ population, the deexcitation mechanisms and lifetimes, and the cascade time in $\mu \mathrm{p}$.
\end{abstract}

Keywords Muonic hydrogen • Metastable 2S state $\cdot$ Long-lived population • Coulomb deexcitation $\cdot$ Radiative quenching $\cdot$ Kinetic energy $\cdot$ Cascade time

PACS 36.10.Ee -34.50.-s - 32.70.Fw

\section{Introduction}

A measurement of the Lamb shift (2S-2P energy difference) in muonic hydrogen $(\mu \mathrm{p})$, to test quantum electrodynamics (QED), has been discussed for about 40 years now [1]. Later it was established that several percent of the muons populate the $2 \mathrm{~S}$ state when stopped in hydrogen in the 1-1000 mbar pressure range [2-4]. Interestingly, however, one could not observe the expected delayed $\mathrm{K}_{\alpha} \mathrm{X}$-rays from collisional quenching of the long-lived (i.e. near-thermal) $\mu \mathrm{p}(2 \mathrm{~S})$ state. One argued that the kinetic energy (k.e.) of the formed $\mu \mathrm{p}(2 \mathrm{~S})$ atoms was so high that only a small fraction could survive the slowing down to thermal energies. Thus, the conclusion was drawn that the long-lived $2 \mathrm{~S}$ population was too small for a laser resonance experiment.

Ten years ago, however, we came to the conclusion that there is indeed a sizeable long-lived $\mu \mathrm{p}(2 \mathrm{~S})$ population $[5,6]$ and the laser experiment is feasible [7, 8].

R. Pohl ( ()

Max-Planck-Institut für Quantenoptik, Garching, Germany

e-mail: randolf.pohl@mpq.mpg.de 


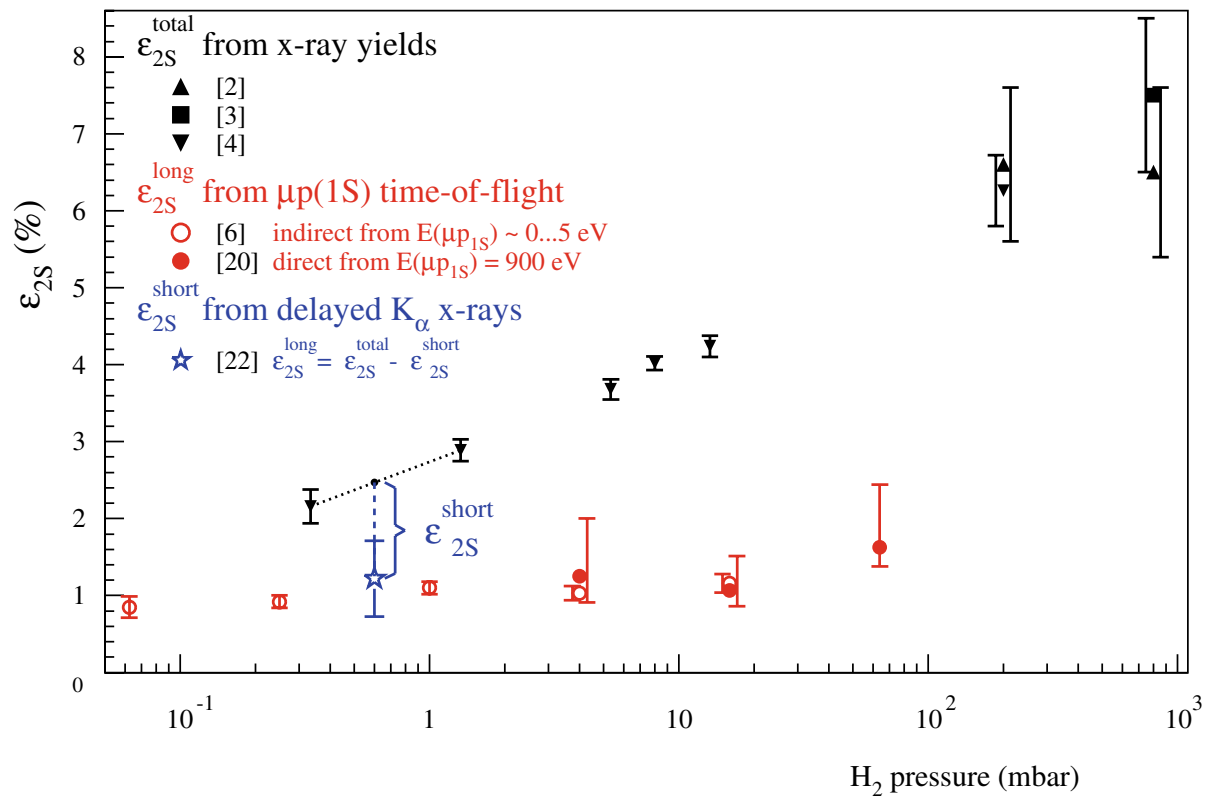

Fig. 1 Black triangles/squares: Total $\mu \mathrm{p}(2 \mathrm{~S})$ population $\epsilon_{2 \mathrm{~S}}^{\text {total }}$ from measured $\mathrm{x}$-ray yields and (1). Red circles: Long-lived $\mu \mathrm{p}(2 \mathrm{~S})$ population $\epsilon_{2 \mathrm{~S}}^{\text {long }}$ from $\mu \mathrm{p}(1 \mathrm{~S}) \mathrm{TOF}$, both indirectly determined (Section 3, open circles), and directly observed (Section 4, solid dots). Blue star: Short-lived $\mu \mathrm{p}(2 \mathrm{~S})$ population $\epsilon_{2 \mathrm{~S}}^{\text {short }}$ from delayed $\mathrm{K}_{\alpha} \mathrm{X}$-rays (Section 5). $\epsilon_{2 \mathrm{~S}}^{\text {short }}$ is plottet as a difference from $\epsilon_{2 \mathrm{~S}}^{\text {total }}$ to indicate the remaining $\epsilon_{2 S}^{\text {long }}$

Therefore we started an experiment at Paul-Scherrer-Institute (PSI), Switzerland with the goal to measure the $2 \mathrm{~S}-2 \mathrm{P}$ energy difference to $30 \mathrm{ppm}$ using laser spectroscopy [9-11], yielding the RMS proton charge radius with an accuracy of $10^{-3}$.

This article summarizes the knowledge about the metastable and short-lived $\mu \mathrm{p}(2 \mathrm{~S})$ population and their quenching mechanisms. We report on the initial $\mu \mathrm{p}$ kinetic energy as well as the cascade time.

\section{Total $\mu \mathbf{p}(2 \mathrm{~S})$ population $\epsilon_{2 \mathrm{~S}}^{\text {total }}$}

The total $\mu \mathrm{p}(2 \mathrm{~S})$ population $\epsilon_{2 \mathrm{~S}}^{\text {total }}$ is the fraction of muons which reach the $2 \mathrm{~S}$ state during the muonic cascade. It is determined by combining the measured $\mathrm{K}_{\alpha}, \mathrm{K}_{\beta}$ and $\mathrm{K}_{>\beta} \mathrm{X}$-ray yields $\mathrm{I}\left(\mathrm{K}_{x}\right)[2-4]$ and the calculated radiative branching ratios [12]

$$
\epsilon_{2 \mathrm{~S}}^{\text {total }}=0.134 \frac{I\left(K_{\beta}\right)}{I\left(K_{t o t}\right)}+0.144 \frac{I\left(K_{>\beta}\right)}{I\left(K_{t o t}\right)} .
$$

Figure 1 shows in black the total $\mu \mathrm{p}(2 \mathrm{~S})$ population $\epsilon_{2 \mathrm{~S}}^{\text {total }}$, which is a function of pressure. Several per cent of all muons create $\mu \mathrm{p}(2 \mathrm{~S})$ atoms, which seemed like good news for a laser resonance experiment. This requires that the laser-induced $\mathrm{K}_{\alpha}$ $\mathrm{X}$-rays must occur well-separated (in time, i.e. delayed) from the prompt K-line $\mathrm{x}$-rays. Therefore a search for long-lived $\mu \mathrm{p}(2 \mathrm{~S})$ atoms was started. 
Fig. 2 Blue histogram: Measured $\mu \mathrm{p}(1 \mathrm{~S})$ kinetic energy distribution at $p_{\mathrm{H}_{2}}=16 \mathrm{mbar}[6]$. Red function: Calculated probability for a $\mu \mathrm{p}(2 \mathrm{~S})$ to survive thermalisation when starting from a given k.e. [17]

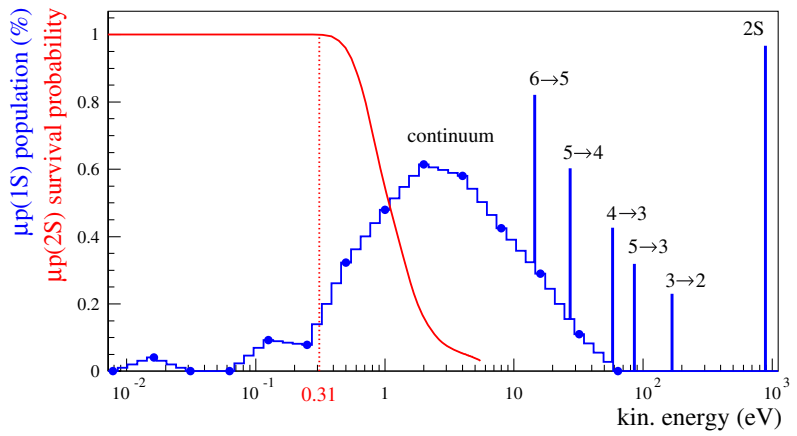

Because of the $0.2 \mathrm{eV} 2 \mathrm{~S}-2 \mathrm{P}$ splitting, the fate of a $\mu \mathrm{p}(2 \mathrm{~S})$ atoms depends on its kinetic energy. Fast $\mu \mathrm{p}(2 \mathrm{~S})$ atoms can quench quickly by collisional excitation to the short-lived $2 \mathrm{P}$ state from which fast radiative de-excitation occurs:

$$
\mu \mathrm{p}(2 \mathrm{~S})+\mathrm{H}_{2} \rightarrow \mu \mathrm{p}(2 \mathrm{P})+\mathrm{H}_{2} \rightarrow \mu \mathrm{p}(1 \mathrm{~S})+\mathrm{H}_{2}+\mathrm{K}_{\alpha} .
$$

This reaction is energetically forbidden for $\mu \mathrm{p}(2 \mathrm{~S})$ atoms with a k.e. below $0.31 \mathrm{eV}$ $(0.2 \mathrm{eV}$ in the $\mathrm{CM}$ system). So the assumption was in the last century, that the main de-excitation mechanism for these slow $\mu \mathrm{p}(2 \mathrm{~S})$ atoms should be quenching via Stark mixing (2P admixed to the $2 \mathrm{~S}$ state) during a collision:

$$
\mu \mathrm{p}(2 \mathrm{~S})+\mathrm{H}_{2} \rightarrow \mu \mathrm{p}(\alpha|2 \mathrm{~S}\rangle+\beta|2 \mathrm{P}\rangle)+\mathrm{H}_{2} \rightarrow \mu \mathrm{p}(1 \mathrm{~S})+\mathrm{H}_{2}+\mathrm{K}_{\alpha} .
$$

A typical collision time of $10^{-14} \mathrm{~s}$ and a $2 \mathrm{P}$ radiative rate of $10^{11} \mathrm{~s}^{-1}$ should result in $10^{3}$ collisions and a lifetime (without $\mu$ decay) of 5 to $25 \mu \mathrm{s}$ at 10 mbar [13-15].

However, the searches for delayed $\mathrm{K}_{\alpha} \mathrm{X}$-rays from process (3) failed, and thus was drawn the conclusion that the long-lived $\mu \mathrm{p}(2 \mathrm{~S})$ population $\epsilon_{2 \mathrm{~S}}^{\text {long }}$ was less than $0.1 \%$, too small for a laser resonance experiment $[2,3]$.

\section{Kinetic energy of the $\mu p$ atoms, slow $\mu \mathrm{p}(2 S)$ and $\epsilon_{2 S}^{\text {long }}$}

It is hard to understand why the long-lived $\mu \mathrm{p}(2 \mathrm{~S})$ population should be so small. Calculations of the slowing down of $\mu \mathrm{p}(2 \mathrm{~S})$ atoms starting with a k.e. between $0.31 \mathrm{eV}$ and a few eV predicted $[16,17]$ that a sizeable amount of $\mu \mathrm{p}(2 \mathrm{~S})$ atoms up to a few eV k.e. should survive the thermalisation (see Fig. 2). Therefore, experiments were undertaken to determine the k.e. distribution of $\mu \mathrm{p}(1 \mathrm{~S})$ atoms [5, 18]. Here we focus on the low pressure regime between 0.06 to 16 mbar [6], where the k.e. of $\mu \mathrm{p}(1 \mathrm{~S})$ and $\mu \mathrm{p}(2 \mathrm{~S})$ atoms are quite similar, because the lower $\mu \mathrm{p}$ cascade is nearly purely radiative and most energy-changing collisions happen above $n=5$.

We stopped muons on the axis of a cylindrical gas target and recorded the time-offlight (TOF) between muon stop and $\mu \mathrm{p}(1 \mathrm{~S})$ arrival at the cylinder walls. The walls were coated with gold and the muon transfer reaction $\mu \mathrm{p}(1 \mathrm{~S})+\mathrm{Au} \rightarrow \mu \mathrm{Au}^{*}$ produces a lot of easily detectable high-energy $\mathrm{x}$-rays. The cylinder geometry has the particular advantage of a very good velocity resolution. Cylinder radii between 3.5 and $29 \mathrm{~mm}$ were used to optimize resolution and sensitivity in the k.e. region below about $10 \mathrm{eV}$. 
Fig. 3 First direct observation of long-lived metastable $\mu \mathrm{p}(2 \mathrm{~S})$ atoms via their non-radiative quenching $\mu \mathrm{p}(2 \mathrm{~S})+\mathrm{H}_{2} \rightarrow \mu \mathrm{p}(1 \mathrm{~S}, 900 \mathrm{eV})$ $+\mathrm{p}+\ldots$, measured at 64 mbar

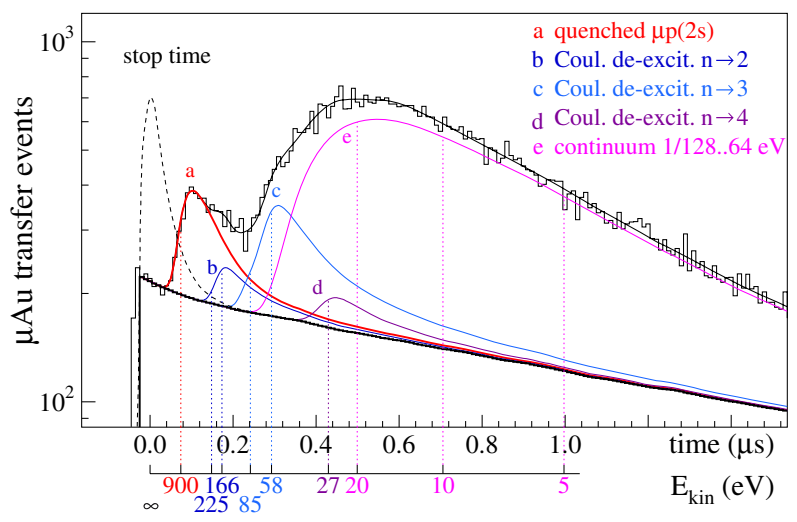

Figure 2 shows the k.e. distribution measured at $p_{\mathrm{H}_{2}}=16$ mbar. It consists of a continuum from thermal energies to several tens of $\mathrm{eV}$, and several distinct peaks from Coulomb de-excitation (CD) at low $n$. The $900 \mathrm{eV}$ peak " $2 \mathrm{~S}$ " originates from quenched $\mu \mathrm{p}(2 \mathrm{~S})$ as explained in Section 4.

The average k.e. rises from $1.3 \pm 0.8 \mathrm{eV}$ at $0.06 \mathrm{mbar}$ to $6.0 \pm 0.5 \mathrm{eV}$ at $16 \mathrm{mbar}$ [6]. We found [6], that the expected fraction of long-lived $\mu \mathrm{p}(2 \mathrm{~S})$ atoms is about $1 \%$, independently on the pressure (red open circles in Fig. 1).

\section{Non-radiative quenching of metastable $\mu \mathrm{p}(2 \mathrm{~S})$ atoms}

The apparent contradiction between the non-observation of radiatively quenched long-lived $\mu \mathrm{p}(2 \mathrm{~S})$ atoms and the expected large population $\epsilon_{2 \mathrm{~S}}^{\text {long }}$ of $1 \%$ can only be solved by the existence of a non-radiative quenching channel for thermalized $\mu \mathrm{p}(2 \mathrm{~S})$ atoms. Furthermore, this channel must be the dominant quenching mechanism.

$$
\mu \mathrm{p}(2 \mathrm{~S})+\mathrm{H}_{2} \rightarrow \mu \mathrm{p}(1 \mathrm{~S}, 900 \mathrm{eV})+\mathrm{p}(1 \mathrm{keV})+\ldots(\text { no } \mathrm{x}-\text { ray })
$$

Here, the $1.9 \mathrm{keV}$ binding energy is shared according to momentum conservation between the $\mu \mathrm{p}(1 \mathrm{~S})$ atom and a proton of the colliding $\mathrm{H}_{2}$ molecule.

The so-called "side-path mechanism" [19], i.e. resonant molecular formation from excited $\mu \mathrm{p}$ atoms with subsequent Coulomb-deexcitation (CD), offered an explanation for the large non-radiative de-excitation rate. A recent calculation of regular (non-resonant) $\mathrm{CD}$ gives, for the first time, also a large enough $2 \mathrm{~S} \rightarrow 1 \mathrm{~S}$ quenching rate [21].

Figure 3 shows the early TOF spectrum measured at 64 mbar in the largest target diameter, which is most sensitive to high k.e. Also shown is the measured stop time, and a k.e. scale obtained by simply converting the $29 \mathrm{~mm}$ target radius into a k.e. of $\mu \mathrm{p}(1 \mathrm{~S})$ atoms. It is evident that the early peak originates from $\mu \mathrm{p}(1 \mathrm{~S})$ atoms with $900 \mathrm{eV}$ k.e. This is the first direct observation of long-lived $\mu \mathrm{p}(2 \mathrm{~S})$ atoms.

The refined analysis [20] taking into account also smaller target diameters, different gas pressures, and the full Monte Carlo analysis of the measured TOF time spectra revealed a $\mu \mathrm{p}(2 \mathrm{~S})$ quenching rate as large as $4.4 \cdot 10^{11} \mathrm{~s}^{-1}$ at LHD, and, again, 
Fig. 4 The stop time, as determined from the $\mu \mathrm{N}$ time spectrum (top), describes the $\mathrm{K}_{>\beta}$ time spectrum (middle) when a time offset is introduced, which is the cascade time. The $\mathrm{K}_{\alpha}$ time spectrum (bottom) can only be explained when one includes the signal from radiatively quenched fast $\mu \mathrm{p}(2 \mathrm{~S})$ atoms

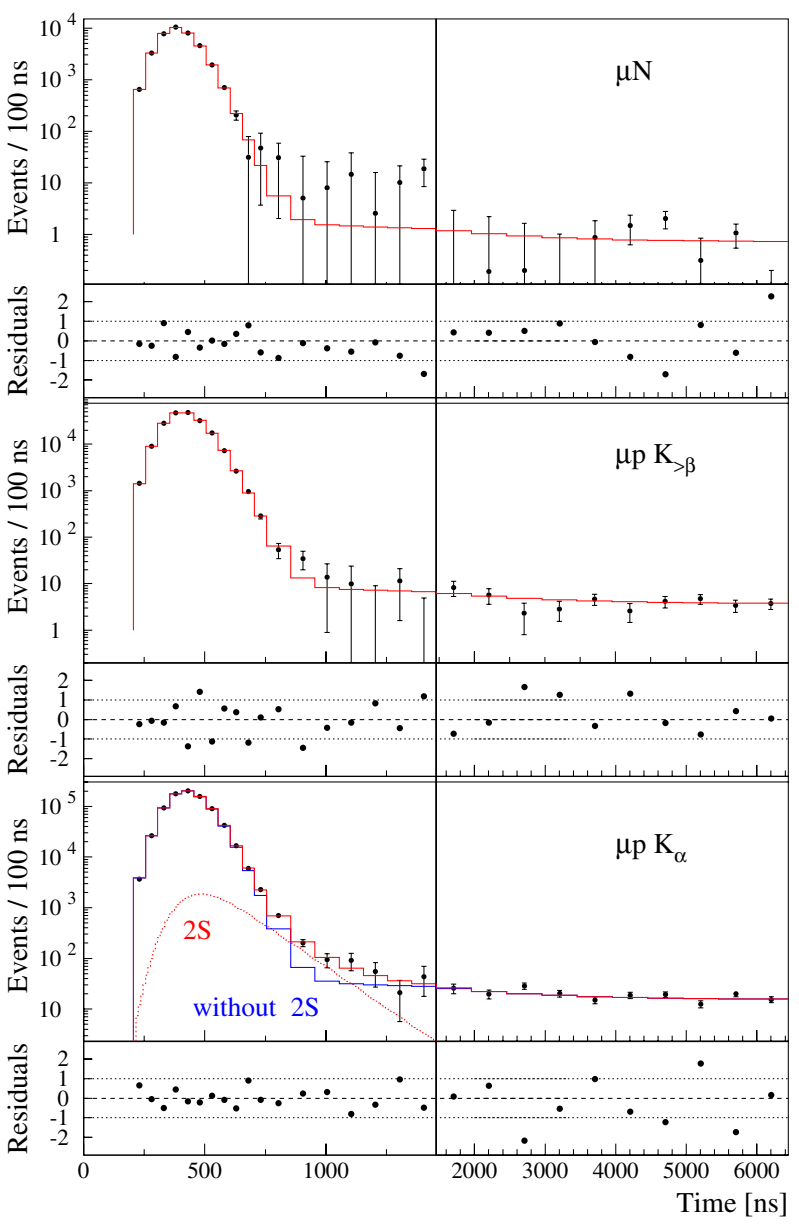

$\epsilon_{2 \mathrm{~S}}^{\text {long }}=1 \%$. The agreement with the indirect determination (Section 3 ) is obvious in Fig. 1.

The direct observation of $\mu \mathrm{p}(2 \mathrm{~S})$ atoms was obviously excellent news for the Lamb shift laser experiment. The unexpectedly large $2 \mathrm{~S}$ quenching rate, however, made this experiment considerably more difficult. The experiment had to take place at $p_{\mathrm{H}_{2}} \leq 1$ mbar, reducing muon stop rate a lot. Also, the laser system had to be rebuilt with a shorter internal delay due to the short $\mu \mathrm{p}(2 \mathrm{~S})$ life time [11].

\section{Radiative de-excitation of fast $\mu \mathrm{p}(2 \mathrm{~S})$ atoms}

Even though the laser experiment has not yet revealed the resonance line, it has produced beautiful data [22]. More than $10^{6}$ muonic hydrogen x-rays have been measured at 0.6 mbar. This is 100 times more than in any other experiment at ultralow $\mathrm{H}_{2}$ gas pressures. And luckily we had a tiny air leak in the $\mathrm{H}_{2}$ target gas system. The $0.4 \%$ of air admixture provided valuable muonic $\mu \mathrm{N}$ and $\mu \mathrm{O}$ calibration data. 
Figure 4 presents the measured time spectra. Muonic nitrogen $\mu \mathrm{N}$ x-rays at $3.08 \mathrm{keV}$ reveal the muon stop time. The $\mathrm{K}_{>\beta}$ time spectrum at $\sim 2.45 \mathrm{keV}$ can be explained exclusively by the stop time, if one introduces a $\mathbf{K}_{>\beta}$ cascade time of $(26 \pm 5)$ ns at 0.6 mbar.

The $\mathrm{K}_{\alpha}$ time spectrum at $1.90 \mathrm{keV}$ reveals a $\mathrm{K}_{\alpha}$ cascade time of (39 \pm 5$)$ ns. More importantly, this $\mathrm{K}_{\alpha}$ time spectrum shows an exponential tail that is not present in the $\mathrm{K}_{>\beta}$ data. This tail comes from the fast $\mu \mathrm{p}(2 \mathrm{~S})$ atoms which are radiatively quenched via (2). The resulting fast population is $\epsilon_{2 S}^{\text {short }}=1.7 \%$ (see blue star in Fig. 1), and its lifetime is $165 \mathrm{~ns}$ at $0.6 \mathrm{mbar}$ [22]. This is the first observation of radiativley quenched, fast $\mu \mathrm{p}(2 \mathrm{~S})$ atoms.

\section{Conclusions}

There seems to be a good understanding of the processes involving $\mu \mathrm{p}(2 \mathrm{~S})$ atoms. Total, long-lived and short-lived population and lifetimes have been experimentally determined. Coulombic, non-radiative deexcitation dominates the lifetime of the long-lived $\mu \mathrm{p}(2 \mathrm{~S})$ atoms. All direct and indirect determinations of the long-lived metastable $\mu \mathrm{p}(2 \mathrm{~S})$ population give the consistent result $\epsilon_{2 \mathrm{~S}}^{\text {long }}=1 \%$.

We have also measured the kinetic energy distributions of $\mu \mathrm{p}(1 \mathrm{~S})$ atoms in the pressure range between 0.06 and $16 \mathrm{mbar}$, as well as the cascade time at $p_{\mathrm{H}_{2}}=0.6$ mbar. Both are important benchmarks for cascade calculations in $\mu \mathrm{p}$.

Open Access This article is distributed under the terms of the Creative Commons Attribution Noncommercial License which permits any noncommercial use, distribution, and reproduction in any medium, provided the original author(s) and source are credited.

\section{References}

1. Di Giacomo, A.: Nucl. Phys. B 11, 411 (1969)

2. Anderhub, H., et al.: Phys. Lett. B 71, 443 (1977)

3. Egan, P.O., et al.: Phys. Rev. A 23, 1152 (1981)

4. Anderhub, H., et al.: Phys. Lett. B 143, 65 (1984)

5. Kottmann, F., et al.: Hyperfine Interact. 119, 3 (1999)

6. Pohl, R.: PhD thesis ETH Zurich No. 14096 (2001)

7. Taqqu, D., et al.: Hyperfine Interact. 119, 311 (1999)

8. Pohl, R., et al.: Hyperfine Interact. 127, 161 (2000)

9. Pohl, R., et al.: Can. J. Phys. 83, 339 (2005)

10. Antognini, A., et al.: Opt. Commun. 253, 362 (2005)

11. Nebel, T., et al.: Can. J. Phys. 85, 469 (2007)

12. Bertin, A., et al.: Lett. Nuovo Cimento 18, 277 (1977)

13. Mueller, R.O., et al.: Phys. Rev. A 11, 1175 (1975)

14. Cohen, J.S., Bardsley, J.N.: Phys. Rev. A 23, 46 (1981)

15. Menshikov, L.I., Ponomarev, L.I.: Z. Phys. D 2, 1 (1986)

16. Carboni, G., Fiorentini, G.: Nuv. Cim. B 39, 281 (1977)

17. Jensen, T., Markushin, V.E.: Eur. Phys. J. D 21, 271 (2002)

18. Abbott, D.J., et al.: Phys. Rev. A 55, 214 (1997)

19. Froelich, P., Flores-Riveros, A.: Phys. Rev. Lett. 70, 1595 (1993)

20. Pohl, R., et al.: Phys. Rev. Lett. 97, 193402 (2006)

21. Popov, V.P., Pomerantsev, V.N.: arXiv:0809.0742 [nucl-th] (2008)

22. Ludhova, L., et al.: Phys. Rev. A 75, 040501 (2007) 